\title{
Effectiveness of Technical Packages for the Apparel Production Process in the Global Apparel Industry
}

\author{
Afroza Akter Rita ${ }^{1}$, Shakinaz Mahamud ${ }^{2}$ \\ ${ }^{I}$ Fashion Design and Technology, BGMEA University of Fashion and Technology (BUFT), Dhaka, Bangladesh. \\ ${ }^{2}$ Fashion Design and Technology, BGMEA University of Fashion and Technology (BUFT), Dhaka, Bangladesh.
}

\begin{abstract}
The apparel industry is one of the biggest economic sectors in the world. It is one of the most important sources of income for many parts of the world economy. It plays a pivotal role in developing a countries economy in terms of revenue generation and creation of employment. The apparel industry is one of the powerful sources of industrial employment, providing jobs for millions of people. The industry is undergoing a drastic change due to global sourcing and high level of price competition. Consumer behavior and disposable income increases when favorable demographic factors changes (Curtin, R. T. 1982). People are focused more on branded apparel and it has resulted in a positive growth in the global apparel market (De Mooij, M., 2013). Global exports of apparel which was 108 billion USD in 1990, increased drastically to 453 billion USD in 2004, which is a positive of 138\% increase during the last 14 years (He, L. 2011). Asian countries contribute to a 50\% of the total global apparel exports (Gereffi, G., \& Memedovic, O. 2003).To become successful in the industry, it is very important to understand its structure, including both the manufacturing and retail side, as well as to be update knowledge of the market, product trends and a well-developed technical package for the apparel production. Technical packages hold the driving seat of the apparel production. This study shows the importance and effectiveness of technical packages for apparel production in the apparel industry.

Keywords: Apparel Industry, Global Apparel Industry, Production Process, Tech Pack, Technical Details.
\end{abstract}

\section{Introduction}

In today's global apparel industry, garments that are designed domestically are often manufactured overseas. The technical package, a series of forms that define a garment's specifications, is critical to ensuring that a particular style is executed correctly and in the most cost and time-efficient manner possible. Apparel Production Management and the Technical Package present the basics of production management and provide clear instructions for creating each component of a production package. Tech pack is the short form of the apparel technical package. Tech packs are the universal form of the fashion and apparel industry. It explains all the details of a particular garment need to be communicated, understood, discussed and brought to life by a team of a people from a different who speaks a different language. The document used throughout the process of apparel development is the technical package or tech pack (Lee, J., \& Steen, C. 2014). Tech pack is a written guideline for a style that includes all the specific information related to providing a certain garment. It is the package of information or a complete information package for developing the samples and executing the production. Tech packs are digital illustrations of designs that show relevant views, proportions, materials and other information that is integral to making design. It is the best starting point for conveying an original design. A well-developed tech pack will greatly reduce production and manufacturing time, costs and in turn position of the organization for high quality and well-crafted garments (Kumar, S., \& Gupta, Y. 2016). It includes all the details of any specific style of the garment. This document is usually prepared by the designer and finalized in consultation with the merchandisers and then forward to bulk sampling department or to the production department for the reference and guide for bulk manufacturing. It is sent by the buyer to the garment merchandisers at the beginning of a garment export order.

\section{Materials And Methods}

In fashion and apparel sector, one of the most and important elements of creating a successful fashion line is the Tech pack. Tech pack is the starting point for conveying an original garment. It is a complete and transparent information package for developing the samples and executing the production. Tech packs are designed by Industry experts. There are teams who design and execute it. 
Effectiveness of Technical Packages for The Apparel Production Process in the Global Apparel..

\subsection{Tech pack design process}

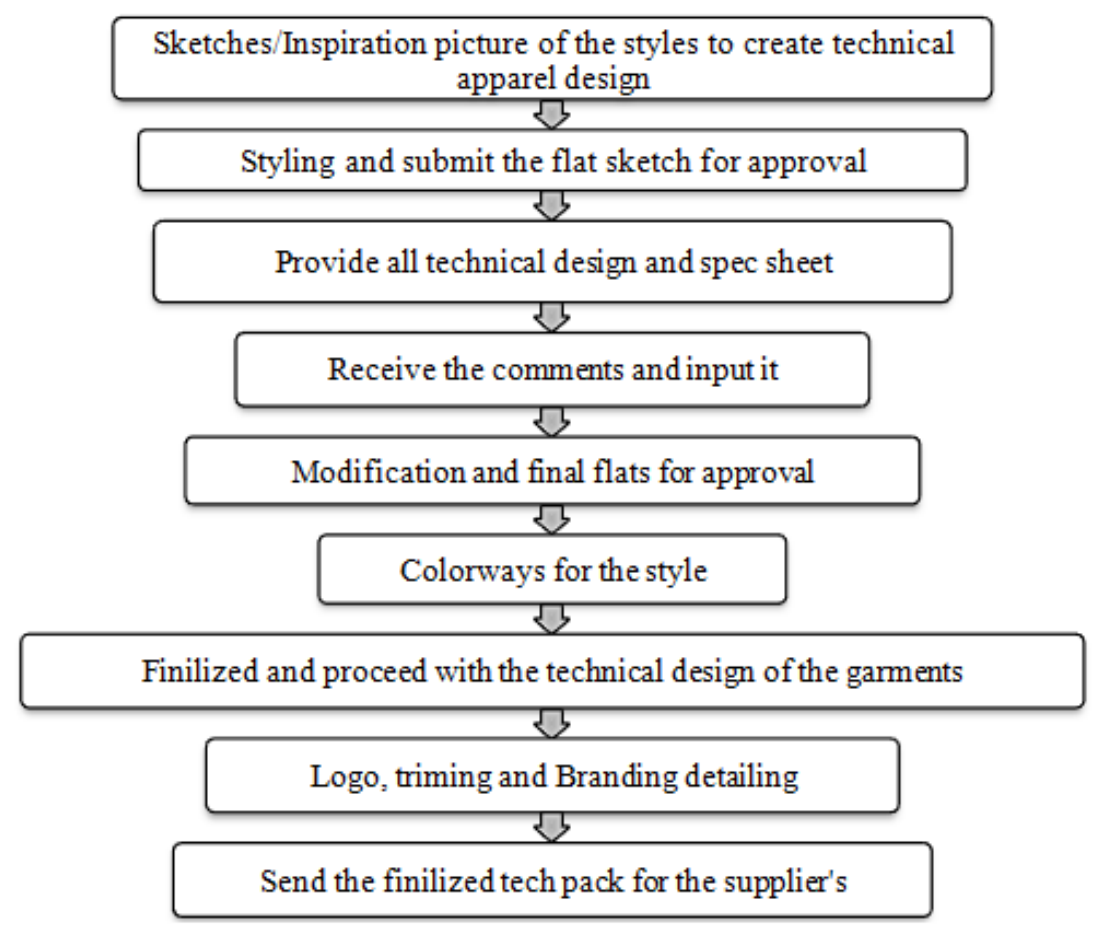

Figure 1: Flowchart of Technical Package Design.

\subsection{Components of tech pack}

1.2.1 Design of the product or Flat Sketch: Design of the product means outlook and Flat sketch means the technical sketch of the required garments or products. These should be including front view, back view and also side view. This views show accurate layout of proportion and measurement of required product or garments. Technical sketches need to black and white format.

1.2.2 Style number: Style number means code number. It indicates the specific no. of the specific style of the garments. Style number also shows year, season, color and one specific reference no. which show the individual style.

1.2.3 Color specification: It means the specific color of particular garments. Need to clear instructions of specific color, shade, and color name \& code.

1.2.4 Fabric details: Details information of the fabric like width of the fabric, fabric weight, fabric cost, fabric consumption, fabric design, print, fabric wash, shrinkage percentage, testing method etc. is needed for a tech pack. Along with this information sometimes buyer may provide additionally swatch of the fabric, scan of the print design depending on a particular style.

1.2.5 Stitching and Construction details: It contains detailed information about stitch type, stitch thread type, stitch class, stitch length, seam class, and order of assembly for the product.

1.2.6 Print details: It includes all the technical details about printing like print size and placement. It also includes color of print and any special treatment of print.

1.2.7 Embroidery details: It includes different types of information like size, placement, color and materials about the required embroidery for specific product or garments.

1.2.8 Washing details: Washing details are the washing care instructions for the garment. It means types of wash like softness and hardness. It contains special washing care information if needed. It also contains ironing information of the required garments.

1.2.9 Trim details: Trims means accessories, needed for the particular garments. It contains the particular items about all of the trims, which may include type of zipper, zipper size; types of button, button size, elastics, type of thread, thread color; lace, interfacing, poly bag, tissue, pin and labels used in the particular product.

1.2.10 Point of measurement (POM): Point of measurement is one of the most important aspects of a tech pack. It contains all the in details measurement of a finished garments and make sure that every measurement is included in the specification sheet. As per buyer instructions, flexible measurement tape is needed for the measurements taken. Measurement are to be taken by keeping garment flat on the table, which are needed to follow at sampling stage and production stage as well. 
Effectiveness of Technical Packages for The Apparel Production Process in the Global Apparel..

1.2.11 Size chart and grade rule: Size chart or measurement sheet contains various size measurements of the required garments. It also has the grade rules of the particular size of the required items.

1.2.12 Bill of Materials (BOM): Bill of materials contains a check list of materials, items, processes, vendors and consumptions used in preparing the garments. It is also used to prepare actual cost of the garments.

1.2.13 Label details: It contains various types of label such as main label, care label, size label etc. Label details also include the placement of the label as per buyer requirement.

1.2.14 Testing method details: It contains the testing process to quantify shrink percentage or other dimensional changes of goods used in the product.

1.2.15 Special treatment details (if any): If the garment needs any treatment for washing and dyeing then it should be included and clear instructions is needed. Special treatment like water proof, fire proof, and soil realized etc.

1.2.16 Folding and packaging details: It contains how to fold or hang the garment and how the garment should be packaged and any materials required such as tissue, card bard and poly bags.

1.2.17 Fit history: This page is used to record the measurements of each subsequent sample and it will compare the actual prototype measurements against the spec to determine whether it is on spec or off spec for each point of measure.

1.2.18 Sample evaluation comments: This page is the place to add notes, record changes, confirm details, and make revisions, if necessary. The comments will be justified by the factory and used to make the next sample. The latest information is added in this page.

1.2.19 Necessary comments related to the products or products: If buyers needed to deliver some comments related to the required garments manufacturing methods then he or she can use this option.

\subsection{Pre-production activities}

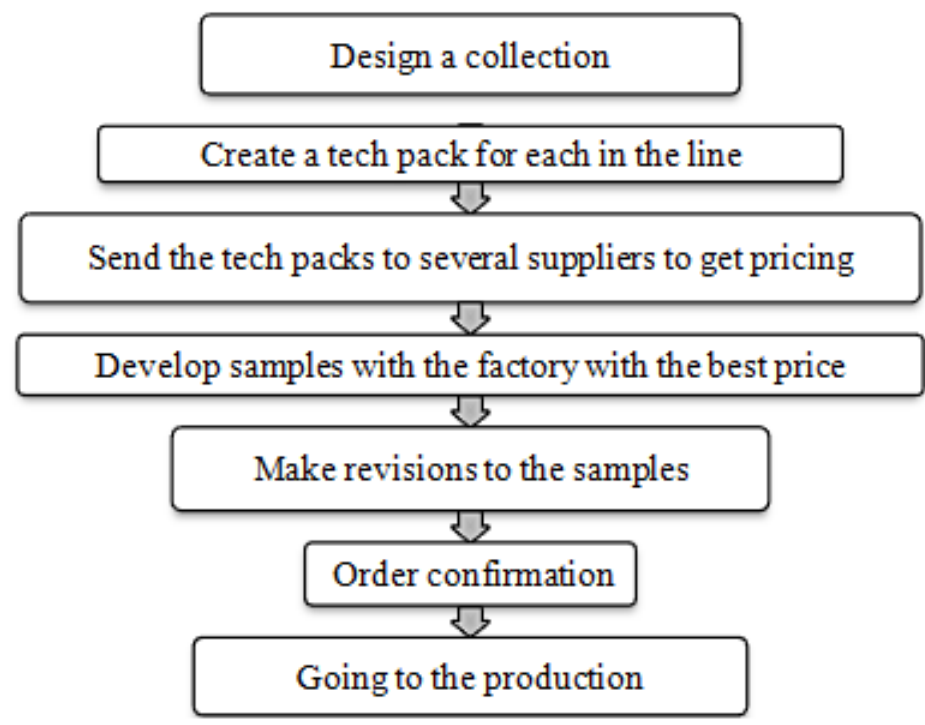

Figure 2: Flowchart of Pre-production Activities.

\subsection{Apparel Production Processes}

An apparel production requires a team workers that include fashion designers to design and sketches of clothing including front view, back view and side view with all the details of color, thread, buttons, zipper, fabrics etc. ; a technical designers will figure out how a sketch can be brought to life. Technical designers begin to create a tech pack will include details for the production team such as flat sketches of garments, points of measurements, sewing details, bill of materials, wash description, label or hangtag placement, packaging information and instructions. The information within the tech pack is crucial for the production team, as all of the information has to be accurate in order to create a garment. Once the technical package is finished, it is sent by email to the factory, along with the pattern of the garment or accessory, to the production team for prototyping and creates a first fit sample. When the first sample is created, it will be checked for any specification issues and if it is out of tolerance it is noted in the fit comments. Then, a fitting is scheduled with a fit model and any other adjustments are noted as well. Once adjustments and fit comments have been made, the technical designer will send the comments to the pattern maker, designer and the factory. This fit process has been repeated until the desire look and fit will be achieved according to tech pack. Once the fit process has been approved, the tech pack will be sent to the production staff for mass production. 


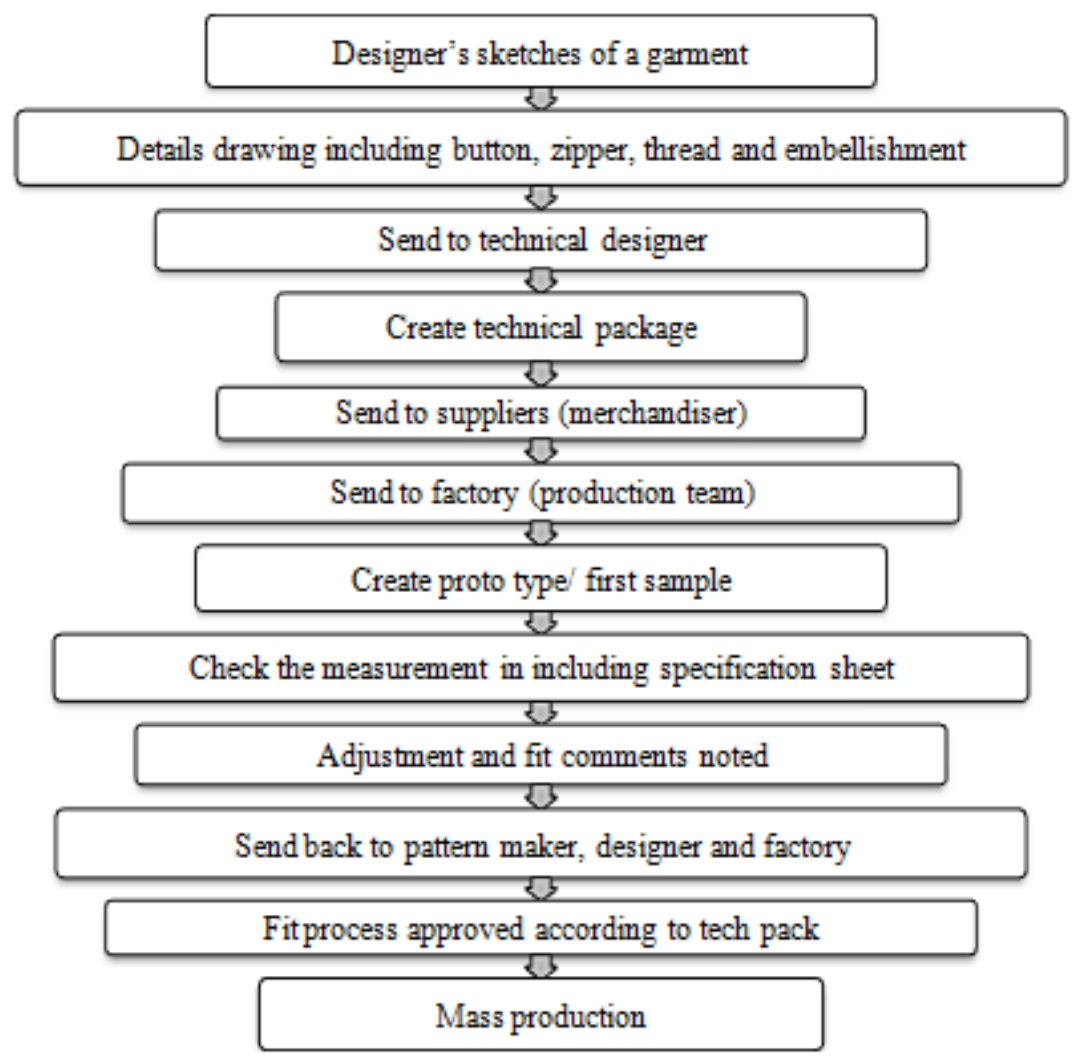

Figure 3: Flowchart of Apparel Production Process.

\section{Importance of Technical packages}

\section{Results}

- Tech pack provides right decision in right time in right place.

- A developed tech pack is reducing the changes of misunderstanding between buyer and supplier.

- It will reduce errors and save time in production, reduce issues with communication, and ultimately save money and frustration.

- Tech packs contain clear instructions on construction, stitching, materials and fit. So everything is present in one document.

- $\quad$ Through tech pack production runs are smooth and quality assured.

- Every tiny small and important in-detail to clothing manufacturer in terms of a tech pack to make sure the production piece comes right.

- Tech packs makes the production process smoother and faster.

- It helps the factory to estimate the resources required for construction of a particular style.

- Tech pack will leave no room for interpretation causing the product to be consistent from sampling through to production.

- A tech pack will be so specific and comprehensive that could be send any factory around the world and they will be able to make the required garment with no additional explanation.

\section{Discussion}

A technical package integrates all information that a manufacturer needs to produce the entire garment. It ensures manufacturer and apparel brand are on the same page. Tech packs significantly reduce the time and afford required producing the garments. A well-developed tech pack saves time and money by way of systematic construction detailing and improves efficiency and productivity. It protects against misinterpretation on style detailing. It is not complete unless it is more detailed than the think it should be. The apparel industry should be able to create the entire garment from start to finish by following the instruction of technical package, without having to ask any questions. It is the heart of the apparel production. Without tech pack production is just impossible. Tech packs including every detailing that will be no room for interpretation causing the product to be consistent from sampling through to production. A great tech pack will be so clear and specific that could be sending to any factory around the world and it will be able make the garment with no additional explanation. 


\section{Conclusion}

Apparel industry represents a dynamic sector in the global trade. The industry is expected, estimated and generate a considerable amount of revenue and employment in a global perspective. Manufacturing apparels is one of the most in-demand businesses in present arenas of this trade. Technical package is one of the most critical steps that an organization must properly execute of effectively manufacture a garment. Tech packs is the most important effective communication tool for the garment manufacturer. Without tech pack it is impossible to move production. Buyer negotiates the tech pack with the production merchandiser in order to get the desired outcome with the desired quality and aesthetics. Through tech pack, it is possible to control the quality of the product throughout the production procedure.

\section{Acknowledgement}

I would like to extend my deepest gratitude towards my colleagues, BGMEA university of Fashion and Technology, Dhaka, Bangladesh. I am highly acknowledged to my co-author for consistent support and guidance in correct direction.

\section{Reference}

[1]. Curtin, R. T. (1982). Indicators of consumer behavior: The University of Michigan surveys of consumers. Public Opinion Quarterly, 46(3), 340-352.

[2]. De Mooij, M. (2013). Global marketing and advertising: Understanding cultural paradoxes. Sage Publications.

[3]. Gandhi, A., \& Sharma, S. (2013). An Analysis of Responsible Factors for Merchandiser's Performance and Role in Apparel Industry. Metamorphosis: A Journal of Management Research, 12(1), 30-46.

[4]. Gereffi, G., \& Memedovic, O. (2003). The global apparel value chain: What prospects for upgrading by developing countries (pp. 1-40). Vienna: United Nations Industrial Development Organization.

[5]. He, L. (2011). A Study of the Shifting Patterns of Global Sourcing in the US Textile and Apparel Industry (Doctoral dissertation, Washington State University).

[6]. Kaminski, B. (2006). Foreign Direct Investment and Central Europe's Reintegration into Global Economy•. University of Maryland, Working Paper, february.

[7]. Kumar, S., \& Gupta, Y. (2016). An Approach for Effective Communication between Buyer and Vendor in Sampling Program. NIFT.

[8]. Lee, J., \& Steen, C. (2014). Technical sourcebook for designers. A\&C Black. 